\title{
Experimental and DFT insights of Zn-doping effects on the visible-light photocatalytic water splitting and dye decomposition over $\mathrm{Zn-doped} \mathrm{BiOBr}$ photocatalysts
}

Junqiu Guo ${ }^{\mathrm{a}}$, Xin Liao ${ }^{\mathrm{a}}$, Ming-Hsien Lee ${ }^{\mathrm{b}}$, Geoff Hyett ${ }^{\mathrm{c}}$, Chung-Che Huang ${ }^{\mathrm{d}}$, Daniel W. Hewak ${ }^{\mathrm{d}}$, Sakellaris Mailis $^{\mathrm{d}}$, Wei Zhou ${ }^{\mathrm{a}, \mathrm{e}}$, Zheng Jiang ${ }^{\text {a* }}$

\footnotetext{
a. Faculty of Engineering and the Environment, University of Southampton, Southampton, SO17 1BJ, UK

b. Department of Physics, Tamkang University, Taipei 25137, Taiwan, R.O. China

c. Department of Chemistry, University of Southampton, Southampton, SO17 1BJ, UK

d. Optoelectronics Research Centre, University of Southampton, Southampton, SO17 1BJ, UK

e. Key Laboratory of Functional Inorganic Material Chemistry, Ministry of Education of PR China, Heilongjiang University, Harbin, 150080, PR China
}

\begin{abstract}
Synergetic experimental and DFT insights of energy band structures and photogenerated reactive intermediates are indispensable to design impurity-doped photocatalysts for photocatalytic environment remediation and solar fuels. Herein, despite the larger bandgap (Eg), $\mathrm{Zn}$-doped $\mathrm{BiOBr}$ samples exhibited superior activity to $\mathrm{BiOBr}$ in the photocatalytic water splitting but adverse in photodegradation of Rhodamine B under visible-light illumination. Based on the spectral and electrochemical impedance characterisations and DFT simulations, the broader bandgap of Zn-doped $\mathrm{BiOBr}$ was explicitly assigned to more positive valence band maximum (VBM) and more negative conduction band minimum (CBM). The enhanced photocatalytic water splitting on $\mathrm{Zn}$-doped $\mathrm{BiOBr}$ was assigned to the higher redox chemical potentials of charge carriers on respective CBM and VBM, suppressed back reaction and reduced recombination of photogenerated charge carriers. However, the reduced $\mathrm{e}^{-}-\mathrm{h}^{+}$recombination on $\mathrm{Zn}$-doped $\mathrm{BiOBr}$ cannot cancel the adverse influences of its weaker light absorption and dye-sensitisation effects, leading to slower RhB photodegradation.
\end{abstract}

Keywords: photocatalysis, Zn-doped BiOBr, photoelectrochemistry, band structure, DFT

\section{Introduction}

The ever-increasing concerns of energy and environment sustainability have motivated great enthusiasm in photocatalytic environment remediation and artificial photosynthesis that require rational design of effective visible-light photocatalysts and understanding of their working mechanism. The bismuth oxybromide ( $\mathrm{BiOBr}$ ) compound semiconductor has emerged recently as a stable and active visible-light photocatalyst with an indirect bandgap of 2.6 2.9 eV [1-3]. The $\mathrm{BiOBr}$ is of a tetragonal crystal structure, constructed by alternative stacks of $\left[\mathrm{Bi}_{2} \mathrm{O}_{2}\right]^{2+}$ slabs and double $\mathrm{Br}^{-}$slabs through Van de Waals interaction. Between the constituent $\left[\mathrm{Bi}_{2} \mathrm{O}_{2}\right]^{2+}$ and $2[\mathrm{Br}-]$ slabs, there exist 
intrinsic built-in static electric fields that were thought able to promote separation of photogenerated electrons $\left(\mathrm{e}^{-1}\right)$ and holes $\left(\mathrm{h}^{+}\right)$across CBM and VBM [4-6] and beneficial to their transportation to catalyst surface for participating redox reactions or depression of recombination otherwise [7-9]. In order to further modulate bandgap and promote surface photocatalysis of $\mathrm{BiOBr}$, heteroatom doping [1, 10-17] or surface hybridisation with small-bandgap semiconductors or metal nanoparticles [18-21] were attempted successfully. Moreover, the heterogeneous photocatalysis usually involves multiple active species, including photogenerated charge carriers $\left(\mathrm{e}^{-1}\right.$ and $\left.\mathrm{h}^{+}\right)$and derived active intermediates, though their respective roles in the photocatalysis are under debating [10, 22]. For instance of photocatalytic dye degradation, the photoexcited dye can transfer $\mathrm{e}^{-1}$ or $\mathrm{h}^{+}$to CBM or VBM of semiconductor photocatalysts, though the dye-sensitisation effects were not paid enough attention when assess the performance of photocatalysts $[8,23]$. Therefore, it is indispensible to unravel the relevance of photocatalysis with bandstructure and active intermediates to propose a reasonable photocatalysis mechanism[24, 25].
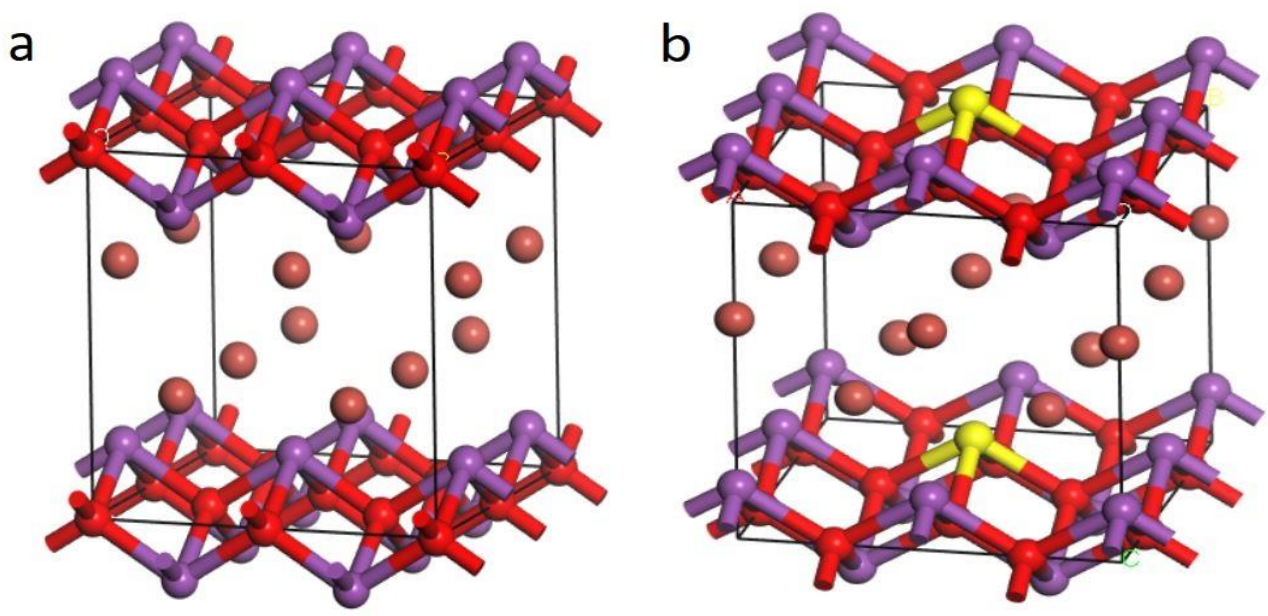

Figure 1 The ball-stick crystal models of $\mathrm{BiOBr}(2 \times 2 \times 1)$ supercell (a) and the derived $1 / 8 \mathrm{Zn}$-doped

$\mathrm{BiOBr}(\mathrm{b})$, where the purple, red, brown and yellow balls refer to $\mathrm{Bi}, \mathrm{O}, \mathrm{Br}$ and $\mathrm{Zn}$ atoms.

Comparing to surface metallisation and hybridisation, doping $\mathrm{BiOBr}$ with heteroatom are very convenient for practical applications $[10,19,26,27]$ because doping to $\mathrm{BiOBr}$ can occur even at ambient conditions. Compared to partial substitution of $\mathrm{Br}$ or $\mathrm{O}$ via mono- or co-doping of $\mathrm{Cl}, \mathrm{I}, \mathrm{N}$ or $\mathrm{S}[10,14]$, the substitutions of Bi by metal are redeemed more flexible to tune the optoelectrical and catalytic properties of Bi-based oxyhalides (BiOX) $[4,10,12,13,15,28]$. Previous DFT simulations suggested transition metal or rare earth dopants (eg, Ti, Fe, Mn, Eu, etc) with unclosed $d$ and $f$ valance electrons can introduce midgap energy levels to the bandstructure of pristine bismuth oxyhalides (BiOX, $\mathrm{X}=\mathrm{Cl}$, Br, I) $[5,6,29,30]$. However, $\mathrm{Zn}$ possesses closed $3 d^{10}$ and $4 s^{2}$ electronic states that 
are supposed to alter the bandstructure of $\mathrm{BiOBr}$ distinctive from other metallic dopants mentioned above, therefore, the particular attention was paid to $\mathrm{Zn}$-doped $\mathrm{BiOBr}$ in this work.

Although enhanced visible-light photodegradation of RhB was observed on the flower-like Zn-doped $\mathrm{BiOBr}$, which was attributed to their large surface areas and enhanced $\mathrm{e}^{-}-\mathrm{h}^{+}$separation[16], the results need further interpretation in terms of the charge carriers or active species. Controversially, Zn-doped $\mathrm{BiOBr}(\mathrm{Zn}-\mathrm{BiOBr})$ displayed lower $\mathrm{RhB}$ photodegradation activity than $\mathrm{BiOBr}$, which was attributed to $\mathrm{H}_{2} \mathrm{O}_{2}$ based reactive hydroxyl radical $\left(\cdot \mathrm{OH}^{-}\right)[31]$. Using the widely adopted semi-empirical electronegativity methods $[3,10,27,32,33]$, the latter research also illustrated the bandstructure of $\mathrm{BiOBr}$ and $\mathrm{Zn}-\mathrm{BiOBr}$ with suitable $\mathrm{CBMs}$ and $\mathrm{VBMs}$ which show potentials enabling dye decomposition and water splitting. These controversial results further motivated us to examine $\mathrm{Zn}$ doping effects on RhB photodegradation and water splitting.

Because the CBM and VBM are pivotal in interpret photocatalytic dye degradation and solar fuels [34], it is necessary to gain deep insights of $\mathrm{Zn}$-doping effects on bandstructures of $\mathrm{BiOBr}$ and $\mathrm{Zn}$ doped $\mathrm{BiOBr}$ through comparative simulations by state-of-the-art DFT program[4-6, 28, 30], to compare with the experimental bandstructures from spectral and photoelectromistry characterisations as well. With UV-Vis spectral techniques, both X-ray photoelectronic spectrum (XPS) and photoelectrochemical characterisations have been evidenced effective and reliable measures to analyse energy band positions (Mott-Schottky Impedance Spectra) and $\mathrm{e}^{-}-\mathrm{h}^{+}$separation efficiency (chronoamperometry)[8, 35]. Moreover, photocatalytic experiments using suitable radical scavengers allow to identify the rate-limit reactive species in photocatalysis [36].

In this work, $\mathrm{Zn}$-doped $\mathrm{BiOBr}$ samples were prepared and applied in photodegradation of $\mathrm{RhB}$ and water splitting. The pristine $\mathrm{BiOBr}$ and $\mathrm{Zn}$-doped $\mathrm{BiOBr}$ with $1 / 8$ and $1 / 16$ fractions of $\mathrm{Bi}$ atoms substituted by Zn were comparatively characterised and simulated by DFT to gain explicit insights into $\mathrm{Zn}$-doping effects. Using radical scavengers, the research also distinguished the effects of bandgap, reactive radicals and dye sensitisation on photocatalytic RhB degradation and water splitting.

\section{Computational and Experimental}

\subsection{Computational details}

The electronic structures of typical $\mathrm{BiOBr}$ and $\mathrm{xZn}-\mathrm{BiOBr}$ samples were simulated using DFT method implementing CASTEP 16.1 code[37]. The supercells of the primitive $\mathrm{BiOBr}$ cell were applied to build the $\mathrm{Zn}$-doped $\mathrm{BiOBr}$ crystal models, where one $\mathrm{Zn}$ atom substitution of one $\mathrm{Bi}$ atom in the $(2 \times 2 \times 1)$ and $(2 \times 2 \times 2)$ supercells will create the respective original models of $1 / 8 \mathrm{Zn}-\mathrm{BiOBr}$ (illustrated in Fig. 1 as an example) and 1/16Zn-BiOBr, corresponding to 1.04 and 2.08 atm\% doping levels. 
In the simulation, GGA-PBE exchange-correlation functional and norm-conserving pseudopotentials were used for geometry optimisation and electronic structure calculations, with considerations of electron spin polarization. For the geometry optimisation using BFGS method, the energy cut-off for the plane wave expansion was set to be $750 \mathrm{eV}$, resulting in a convergence of total energy and residual force tolerance to be within $0.1 \mathrm{eV} /$ atom and $2.0 \times 10^{-6} \mathrm{eV} /$ angstrom, respectively. The $k$-point Monkhorst-Pack (MP) spacing of 0.125/A was adopted when sampling in the Brillouin zones for geometry optimisation of the primitive $\mathrm{BiOBr}$ and the $\mathrm{Zn}$-doped $\mathrm{BiOBr}$ supercells, while the $k$-point MP spacing of $0.0125 / \AA$ was adopted for band structure and density of states (DOS) calculations. The band structures were calculated along the Monkhorst-Pack (MP) grid connecting the high-symmetry k-points of Z (0,0,0.5), A (0.5,0.5,0.5), M (0.5,0.5,0), Г $(0,0,0), \mathrm{Z}(0,0,0.5), \mathrm{R}(0,0.5,0.5), \mathrm{X}(0,0.5,0)$ and $\Gamma(0,0,0)$ in the $k$-space of the first Brilluoin zone, where the two $\Gamma$ points were applied because the MP grid should be closed.

\subsection{Preparation of the $\mathrm{Zn}$-doped BiOBr photocatalysts and photoelectrodes}

The $\mathrm{Zn}$-doped $\mathrm{BiOBr}$ photocatalysts with varying $\mathrm{Zn}$-doping levels $\left(\mathrm{Zn}_{\mathrm{x}} \mathrm{Bi}_{(1-\mathrm{x})} \mathrm{OBr}\right.$, hereafter denoted as $\mathrm{xZn}-\mathrm{BiOBr}$, where $\mathrm{x}$ is the $\mathrm{Zn}$-doping level) were prepared via a simple co-precipitation method. Typically, under rigorous stirring, $20 \mathrm{~mL} \mathrm{KBr}(0.2 \mathrm{M}) / \mathrm{NaOH}(0.2 \mathrm{M})$ mixed solution was poured into $20 \mathrm{~mL} 20 \%$ acetic acid aqueous solution containing calculated amount of $\mathrm{Bi}\left(\mathrm{NO}_{3}\right)_{3}$ and $\mathrm{Zn}\left(\mathrm{NO}_{3}\right)_{2}$, where the $\mathrm{Zn} / \mathrm{Bi} / \mathrm{Br}$ molar ratios of $\mathrm{x}:(1-\mathrm{x}): 1$ were maintained for obtaining $\mathrm{xZn}-\mathrm{BiOBr}$ samples. Upon mixing the above solutions, pale yellowish precipitates were observed immediately, and the systems' final $\mathrm{pH}$ was adjusted to 12.0 using $0.3 \mathrm{M} \mathrm{NaOH}$ solution. The resulting mixtures were stirring for $6 \mathrm{~h}$ and ageing overnight before filtration and washing thoroughly by deionised water (DI). The received wet gels were dried in oven under $60^{\circ} \mathrm{C}$ for $24 \mathrm{~h}$ to obtain the $\mathrm{xZn}-\mathrm{BiOBr}$ photocatalysts.

The photoelectrodes of $\mathrm{xZn}-\mathrm{BiOBr}$ photocatalysts were fabricated by doctor-blade coating of the photocatalyst pastes onto clean ITO/glass slices $(1.5 \mathrm{~cm} \times 1.5 \mathrm{~cm}$, resistance of $15 \Omega / \mathrm{sq})$ which were pre-washed alternatively by absolute ethanol and DI water under ultrasonication ( $40 \mathrm{kHz}, 5 \mathrm{~min}$ each). The pastes of photocatalysts were prepared by mixing $0.1 \mathrm{~g}$ photocatalysts with $100 \mu \mathrm{L}$ ethanol/water (3:1) solution. $10 \mu \mathrm{L}$ of photocatalyst paste was dropped on the dry clean ITO/glass fixed on flat bench using scotch tape to expose $1 \times 1.5 \mathrm{~cm}^{2}$ area, and then slowly rolled a clean glass rod to cast the film. The casted films were then dried at $60^{\circ} \mathrm{C}$ for $24 \mathrm{~h}$ before photoelectrochemistry tests.

\subsection{Characterisations}

All the X-ray diffraction data were collected from the Rigaku SmartLab X-ray diffractometer, using $\mathrm{Cu}-\mathrm{K} \alpha 1$ radiation $(\lambda=0.154056 \mathrm{~nm})$ and a scan rate of $0.05^{\circ} 2 \theta / \mathrm{s}$, to determine the crystal phases of 
the samples. The UV-vis diffuse reflectance spectra were obtained on Perkin Elmer Lambda 950 UV/Vis/NIR spectrophotometer equipped with a $150 \mathrm{~mm}$ snap-in integrating sphere for capturing diffuse and specular reflectance, where $\mathrm{BaSO}_{4}$ was used as standard reflectance. The acquired lattice parameters and bandgap energies were listed in Table 1.

X-ray photoelectron spectroscopy (XPS) was performed on a Thermo Scientific Escaplab $250 \mathrm{~K}$ alpha photoelectron spectrometer using monochromatic Al-K $\alpha$ radiation. Survey and Valence band spectra were collected in the range $0-1100 \mathrm{eV}$ (binding energy) at pass energy of $160 \mathrm{eV}$. Peak positions were calibrated to carbon and fitted using CasaXPS software. The morphologies of the samples were measured on JSM59 SEM manufactured by JEOL on which Energy Dispersive X-Ray (EDX) analyser was installed to analyse the composition of specimens in question.

\subsection{Photocatalytic degradation of RhB and water splitting}

The photodegradation of Rhodamine $\mathrm{B}(\mathrm{RhB})$ on the as-prepared samples was performed at ambient temperature under visible-light irradiation. A $300 \mathrm{~W}$ Xe lamp equipped with a $400 \mathrm{~nm}$ cut-off filter to remove UV light was used as light source, irradiating atop with light intensity of $30 \mathrm{~mW} / \mathrm{cm}^{2}$ and 15 $\mathrm{cm}$ distance away from the beaker containing photocatalyst and $\mathrm{RhB}$ aqueous solution. In a typical photocatalysis experiment, $0.1 \mathrm{~g}$ of the photocatalyst powder was dispersed into $100 \mathrm{~mL} 20 \mathrm{ppm} \mathrm{RhB}$ aqueous solution. Before light irradiation, the mixed system was remained in dark for one hour to establish $\mathrm{RhB}$ adsorption-desorption equilibrium on catalyst surface. The initial concentration $\left(\mathrm{C}_{0}\right)$ was defined as the concentration of $\mathrm{RhB}$ upon adsorption-desorption equilibrium rather than the original concentration of $\mathrm{RhB}$ solution because the photocatalysis occurs on catalyst surface. In order to determine the temporal $\mathrm{RhB}$ concentration $\left(\mathrm{C}_{\mathrm{t}}\right)$ at certain photo-reaction time $(\mathrm{t})$ during photocatalysis, $4 \mathrm{~mL}$ liquid suspension was taken out every 3 mins and centrifuged under $6000 \mathrm{rmp}$ to obtain supernatant solution for sampling by a UV-visible spectrophotometer (PerkinElmer Lampda 750s). Since photodegradation of dilute $\mathrm{RhB}$ in the aqueous solution is a pseudo-first-order reaction, the apparent kinetic coefficient $(k)$ can be calculated form using the equation below:

$-\ln \left(\frac{C_{t}}{C_{0}}\right)=\mathrm{kt}$

Radical scavenging experiments were conducted to identify the rate-limiting reactive species. Because ethylenediaminetetraacetic acid (EDTA), isopropanol (IPA) and p-benzoquinone (p-BQ) are effective scavengers with respective to $\mathrm{h}^{+}$at $\mathrm{VBM}$, hydroxyl radical $(\bullet \mathrm{OH})$ and superoxygen radical due to $\mathrm{e}^{-}$at $\mathrm{CBM}$, they were mixed into $\mathrm{RhB}$ solution respectively to acquire corresponding photodegradation activities for comparing and assessing the contributions of photogenerated $\mathrm{e}^{-}$[38] and $\mathrm{h}^{+}$[39] at band edges into photodegradation. 
The experiments of photocatalytic hydrogen from water splitting were carried out in the similar procedure presented in the previous report [35]. Briefly, $100 \mathrm{mg}$ of as-prepared photocatalysts was taken into a homemade reactor containing $80 \mathrm{~mL}$ deionized water and $20 \mathrm{~mL}$ methanol, to which $\mathrm{H}_{2} \mathrm{PtCl}_{6} \cdot 6 \mathrm{H}_{2} \mathrm{O}(0.5 \mathrm{wt} \%$ to photocatalysts) was added as a co-catalyst. Before photocatalytic testing, the reactor and the entire gas circulating system were de-aerated using a vacuum pump for $30 \mathrm{~min}$. All photocatalytic $\mathrm{H}_{2}$ generation tests were under continuous illumination using an Autolight CELHXF300 xenon lamp (300 W, $100 \mathrm{~mW} / \mathrm{cm}^{2}$ ) equipped with optical cut-off filters to realize visible light irradiation. The photocatalytic $\mathrm{H}_{2}$ production was determined using Agilent gas chromatography (GC, 7900) at the sampling interval of 60 mins per test.

\subsection{Photoelectrochemistry tests}

Photoelectrochemistry measurements of the as-prepared $\mathrm{BiOBr}$ and $\mathrm{Zn}$-doped $\mathrm{BiOBr}$ photoelectrodes were carried out at room temperature in a standard three-electrode cell using the AUTOLAB PGSTAT 302N equipped with FRA spectroscopy. The as-prepared film electrodes, a platinum disk and a saturated calomel electrode (SCE) were used as working electrodes, counter electrode and reference electrode, respectively. The electrolyte supporting solution was $100 \mathrm{~mL} 0.5 \mathrm{M} \mathrm{Na}_{2} \mathrm{SO}_{4}$ solution with constant $\mathrm{pH}$ of 6.5 . The Mott-Schottky (M-S) data were acquired at the optimised frequency of $3000 \mathrm{~Hz}$ in dark, with $10 \mathrm{mV} / \mathrm{s}$ scan rate and $10 \mathrm{mV} \mathrm{AC}$ amplitude. The acquired potentials were transformed to reversible hydrogen electrode scale (RHE) to $\mathrm{pH}$ of 0 .

The quantitative analysis of M-S data to acquire flat band potential $\left(\mathrm{V}_{\mathrm{fb}}\right)$ is based on the MottSchottky law from the plots of $C_{s c}^{-2}$ versus the applied potential bias $\left(\mathrm{V}_{\text {app }}\right)$ :

$$
\frac{1}{C_{s c}^{2}}=\frac{2}{A^{2} \varepsilon_{0} \varepsilon_{r} e N_{d}}\left(V_{a p p}-V_{f b}-\frac{k_{B} T}{e}\right)
$$

where $\mathrm{C}_{\mathrm{sc}}, \mathrm{A}, \mathrm{N}_{\mathrm{d}}, \varepsilon_{r}$ and $\varepsilon_{0}$ are respective to the space capacitance, electrode area $\left(1.0 \mathrm{~cm}^{2}\right.$ in this work), donor density, relative dielectric of semiconductor and vacuum dielectric, while the $k_{\mathrm{B}}, \mathrm{T}$ and $e$ stand for the Boltzmann constant $\left(1.38 \times 10^{-23} \mathrm{~J} / \mathrm{K}\right)$, system absolute temperature ( $293 \mathrm{~K}$ here) and charge of electron $\left(1.602 \times 10^{-19} \mathrm{C}\right)$. Extrapolation linear M-S plot to potential bias axis leads to an interception potential $\left(V_{\text {extro }}\right.$, the corresponding charge energy of $E_{\text {extro }}=e \cdot V_{\text {extro }}$ ), while the slope of the M-S straight plot is proportional inversely to the density of majority carriers $\left(\mathrm{N}_{\mathrm{d}}, \mathrm{e}^{-}\right.$and $\mathrm{h}^{+}$for $\mathrm{n}$-type and p-type semiconductor, respectively)[40]. The acquired $\mathrm{E}_{\text {extro }}$ can be manipulated by the following equations (the inferences were detailed in the ESI) to gain band edges in RHE scale.

$$
\begin{aligned}
& E_{f b \sim S C E}=E_{\text {extro }}-k_{B} T / e \\
& E_{f b \sim R H E}=E_{f b \sim S C E}+E_{S C E \sim R H E}^{0}+\frac{R T}{n F} p H \\
& E_{C B M}=E_{f b \sim R H E}-0.2 e V \\
& \mathrm{E}_{\mathrm{VBM}}=\mathrm{E}_{\mathrm{CBM}}+\mathrm{Eg}
\end{aligned}
$$


The equations 3 4 were applied to calibrate the potential contributions from temperature $\mathrm{T}$ (by $\frac{k_{B} T}{e}$ in eq. 3) and $\mathrm{pH}$ (by $\frac{R T}{n F} p H$ in eq.4), where $\mathrm{R}, \mathrm{n}$ and $\mathrm{F}$ represent the universal gas constant, the number of electrons involved in the electrode reaction and the Faraday constant, respectively. In the equation (5), $0.2 \mathrm{eV}$ was applied because the CBM potential is typical $0.2 \mathrm{~V}$ more negative than flat-band for most n-type semiconductors $[40,41]$. The Eg, $\mathrm{E}_{\mathrm{CBM}}$ and $\mathrm{E}_{\mathrm{VBM}}$ are bandgap, energy positions of CBM and VBM, respectively. The retrieved data of $\mathrm{BiOBr}$ and the $\mathrm{Zn}$-doped $\mathrm{BiOBr}$ were listed in Table 2.

The chronoamperometry tests (I-t plots) were recorded at light on-off cycle operation (on-off time interval of $20 \mathrm{~s}$ ) at open circuit potentials $\left(\mathrm{V}_{\mathrm{OC}}\right)$. The photocurrents acquired from $\mathrm{Na}_{2} \mathrm{SO}_{4}$ electrolyte solution containing $\mathrm{RhB}$ were applied to assess the dye-sensitisation effects. The corresponding chronoamperometrical results were summarised in Table 3.

\section{Result and Discussion}

\subsection{Crystal structure and surface composition}

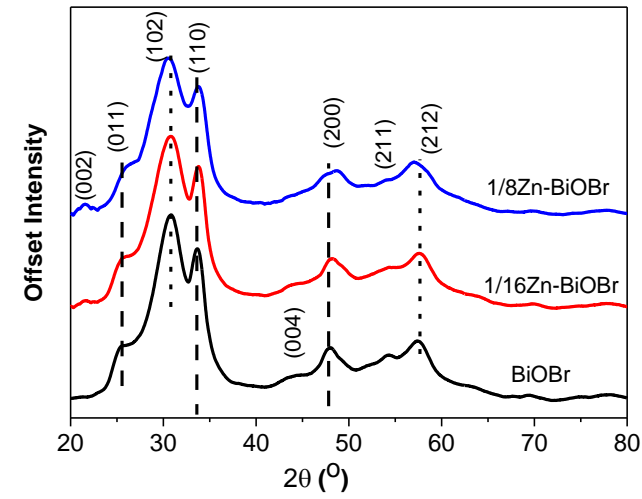

Figure 2 The XRD patterns of $\mathrm{BiOBr}$ and $\mathrm{Zn}$-doped BiOBr samples

Fig. 2 presents the $\mathrm{XRD}$ data of the $\mathrm{BiOBr}$ and $\mathrm{Zn}$-doped $\mathrm{BiOBr}$ samples, where all the characteristic diffraction peaks of the samples can be indexed to the tetragonal phase BiOBr (JCPDS 73-2061), without $\mathrm{ZnO}$ diffraction observed [11]. The gradual shifts of characteristic diffraction peaks and the interplane spacing distance shown in the HRTEM image of $\mathrm{Zn}-\mathrm{BiOBr}$ (Fig. S1) suggest that $\mathrm{Zn}$ has been incorporated into the $\mathrm{BiOBr}$ matrix and caused distortion of $\mathrm{BiOBr}$ lattice [11]. The lattice parameters of $\mathrm{BiOBr}$ and $\mathrm{Zn}$-doped $\mathrm{BiOBr}$ samples derived from XRD data are summarised in Table 1 , further revealing that the $\mathrm{Zn}$-doping induces shrinking of lattice parameters and distorts crystal structure. The unit cell shrinkages of the $\mathrm{Zn}$-doped $\mathrm{BiOBr}$ samples can be well assigned to the substitutions of larger $\mathrm{Bi}^{3+}\left(1.03 \AA\right.$ ) by smaller $\mathrm{Zn}^{2+}$ cation (radius of $0.74 \AA$ )[42], which is in good agreement with DFT optimised geometric data and those of previous report [16]. 
Table 1 Experimental and computed lattice parameters and bandgap of pure and $\mathrm{Zn}$-doped $\mathrm{BiOBr}$

\begin{tabular}{lccccc}
\hline & $\mathbf{a}=\mathbf{b} / \mathbf{A}$ & $\mathbf{c} / \mathbf{A}$ & $\mathbf{c / a}$ & ${\mathbf{V} / \AA^{3}}^{3}$ & $\mathbf{E} \mathbf{g} / \mathbf{e V}$ \\
\hline $\mathbf{B i O B r} \_\mathbf{E x p}$ & 3.7573 & 9.7672 & 2.5995 & 137.6224 & 2.42 \\
& 3.8377 & 9.4045 & 2.4506 & 138.5089 & 2.60 \\
$\mathbf{1 / 1 6} \mathbf{Z n}-\mathbf{B i O B r}$ & 3.7421 & 9.2882 & 2.4821 & 130.0656 & 2.76 \\
& 3.8133 & 9.3998 & 2.4650 & 136.6849 & 2.67 \\
$\mathbf{1 / 8} \mathbf{Z n}-\mathbf{B i O B r}$ & 3.7273 & 9.3503 & 2.5086 & 129.9015 & 2.87 \\
& 3.7945 & 9.3595 & 2.4666 & 134.7602 & 2.88
\end{tabular}

Note: the DFT simulated lattice parameters, cell volume and bandgap were listed in shadowed cells, while the experimental results were derived from XRD characterisations and Eg from UV-Vis spectra.

X-ray photoemission spectroscopy (XPS) was applied to analyse the surface elementary composition, the chemistry environment and the electronic interaction of $\mathrm{BiOBr}$ and $\mathrm{Zn}$-doped $\mathrm{BiOBr}$ samples. The XPS survey spectra and core level XPS (Fig.S2 and S3) indicate that the samples with designed chemical composition were successfully prepared, in good agreement with the composition data acquired by EDS spectra as well (Fig. S4). Fig. 3(a d) show the fitted core level XPS spectra corresponding to the $\mathrm{Bi} 4 \mathrm{f}, \mathrm{O} 1 \mathrm{~s}, \mathrm{Br} 3 \mathrm{~d}$ and $\mathrm{Zn} 2 \mathrm{p}$ core electron binding energies, which evidences cationic $\mathrm{Zn}$ was incorporated into $\mathrm{BiOBr}$ and systematically altered elemental binding energies (B.E.). The attributions of the core level XPS were presented in the electronic supporting information (ESI, S3). More importantly, significant and systematic red shifts of $\mathrm{Bi}, \mathrm{O}, \mathrm{Br}$ binding energies (Fig. 3a c) are observed from the core-level XPS spectra of $\mathrm{Zn}$-doped $\mathrm{BiOBr}$, owing to the fact that $\mathrm{Zn}$-dopant donates electrons to adjacent more electronegative $\mathrm{Bi}, \mathrm{O}, \mathrm{Br}$ atoms and thus enhances their core electron densities. The red-shifts of $\mathrm{Br} 3 \mathrm{~d}$ binding energy may be partly arisen from the weakened Van de Walls forces between the $\left[\mathrm{Zn}_{2 \mathrm{x}} \mathrm{Bi}_{2-2 \mathrm{x}} \mathrm{O}_{2}\right]^{(2-\mathrm{x})+}$ and $\mathrm{Br}^{-}$slabs as $\mathrm{Zn}^{2+}$ substituting $\mathrm{Bi}^{3+}$. The blue shifts of Zn 2p XPS (Fig. 3d) as increasing Zn-doping levels support the electron donation effects of Zn-dopant. 

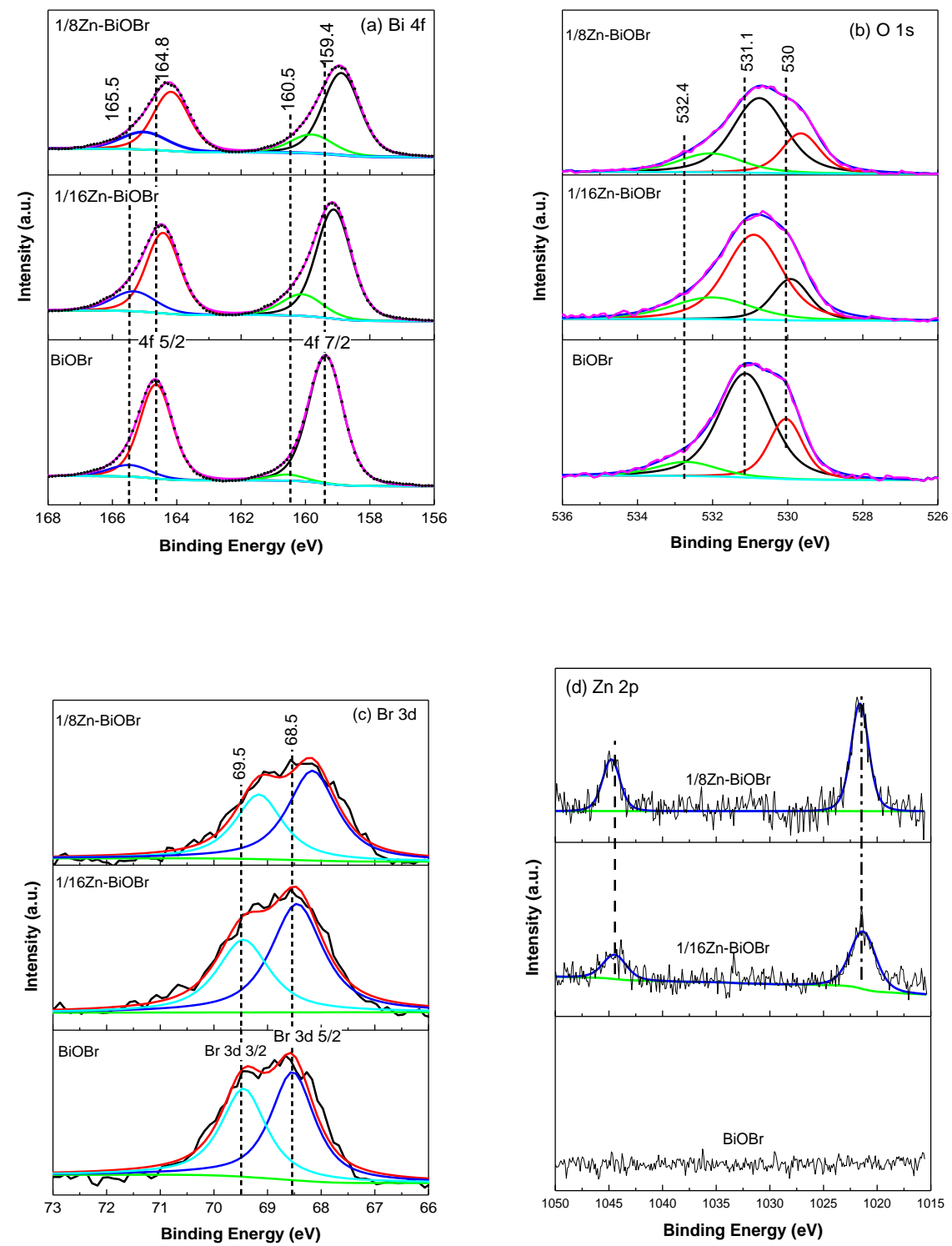

Figure 3 Core level XPS of Bi $4 f(a), O 1 s(b), B r 3 d(c), Z n 2 p(d)$ of BiOBr and $\mathrm{Zn}$-doped BiOBr samples

\subsection{Optoelectronic properties}

UV-Vis diffuse reflection absorbance spectra (UV-Vis-DRS) and corresponding Tauc plots were compared in Fig. 4 to gain light absorption properties and bandgap energies of the photocatalysts. In a broad wavelength region up to $600 \mathrm{~nm}$, BiOBr exhibits stronger light absorption than $\mathrm{Zn}$-doped BiOBr samples (Fig. 4a), suggesting that the increase of $\mathrm{Zn}$-doping level causes gradual blue-shifts of the absorbance edges. However, the significant drifts in the absorbance spectra, which are due to the hue and specular reflection of the samples, hindered deriving accurate bandgap energies. The UV-VisDRS spectra were transformed into Tauc plots (Fig. 4b) implementing Kubelka-Munk equation. It was found $\mathrm{Zn}$-doping did not change the indirect transition characteristic of $\mathrm{BiOBr}$, as accordance with DFT calculations (see Fig. 5). The derived optical bandgap (Eg) of $\mathrm{BiOBr}$ is $2.42 \mathrm{eV}$, smaller 
than those of the $1 / 16 \mathrm{Zn}-\mathrm{BiOBr}(2.74 \mathrm{eV})$ and $1 / 8 \mathrm{Zn}-\mathrm{BiOBr}(2.87 \mathrm{eV})$. The results suggest that $\mathrm{Zn}$ doping broadens the bandgap of $\mathrm{BiOBr}$, in coincidence with the Eg values reported for $\mathrm{BiOBr}$ and $\mathrm{Zn}$ $\mathrm{BiOBr}$ samples via CTAB-directed synthesis[31]. However, the influences of Zn-doping on bandgaps of $\mathrm{BiOBr}$ in our work differ from those of the solvothermal-synthesised $\mathrm{Zn}$-doped BiOBr nanoflowers[16]. Their smaller bandgaps of $\mathrm{Zn}-\mathrm{BiOBr}$ nanoflowers are supposed to due to the hierarchical structure and the structure defects as reducing solvents involved therein.
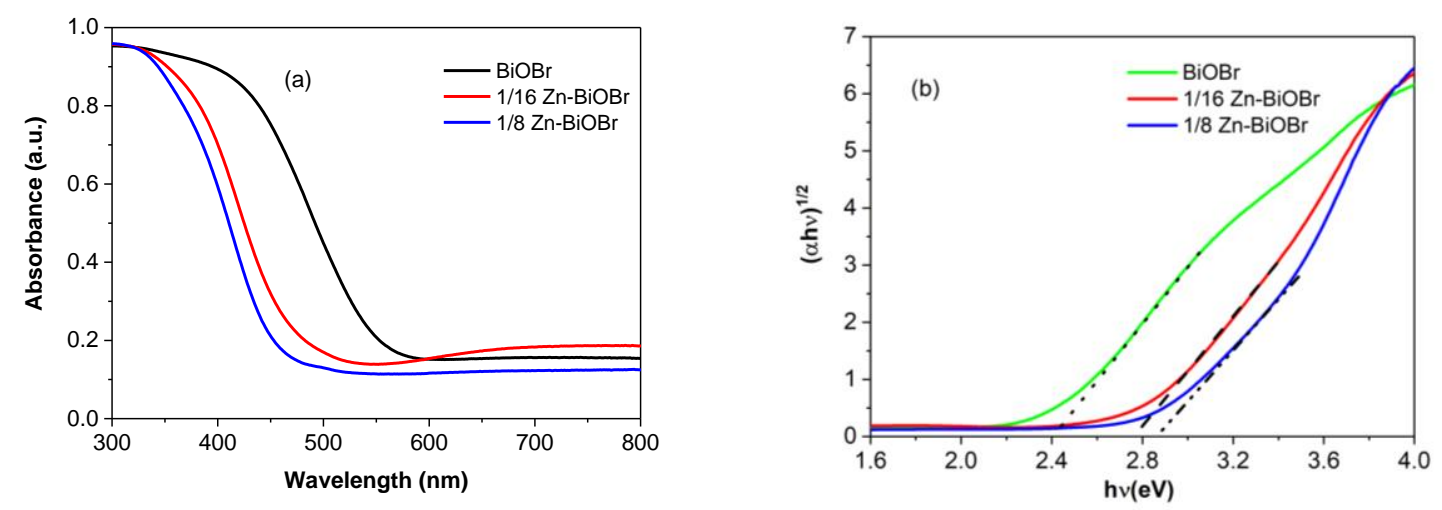

Figure 4 The UV-Vis absorbance (a) and tauc plots (b) of BiOBr and Zn-doped BiOBr samples.

Implementing GGA-PBE exchange-correlation functional in CASTEP16.1, the electronic structures of the materials simulated. As shown in Fig. 5, the computed electronic band-structures of $\mathrm{BiOBr}$ and $\mathrm{Zn}$-doped $\mathrm{BiOBr}$ samples are projected in the first Brillion zone where Fermi energy levels were set at the top of VBM for convenience. The electronic states at VBM and CBM of $\mathrm{Zn}$-doped BiOBr are less dispersive (smaller curvature) than those of $\mathrm{BiOBr}$, suggesting their corresponding $\mathrm{VBM} \mathrm{h}^{+}$and $\mathrm{CBM}$ $\mathrm{e}^{-}$are heavier and less active because the charge effective and mobility are directly proportional to the band wave curvature. The computed $\mathrm{Eg}$ values of $\mathrm{Zn}$-doped $\mathrm{BiOBr}$ are larger than that of $\mathrm{BiOBr}$, highly consistent with the experimental data (Table 1) $[5,6]$, which concretely support the experimental findings that $\mathrm{Zn}$-doping broadens bandgaps.

In contrast, previous DFT research suggests that metal-dopants with partially occupied $d$ or $f$ shells narrow bandgap of BiOBr by introducing impurity-induced mid-gaps $[4,28]$. There is no impurity mid-gap observed in band gap regions of $\mathrm{Zn}-\mathrm{BiOBr}$ materials, which is reasonable because the electrons on closed $3 d$ orbitals of $\mathrm{Zn}$ are not interactive enough to bring electronic states to bandgaps. $\mathrm{Zn} 3 d^{10}$ electrons are found mainly contributing to deeper bands, localizing at $\sim 7 \mathrm{eV}$ more positive (deeper) than VBM (Fig. S5). The total electron density of states (DOS) and Zn partial DOS (PDOS), as shown in Fig. S6, further confirm the negligible contributions of Zn $3 d$ orbitals to bandgaps.

Furthermore, the simulated $\mathrm{CB}$ and VB band edges suggest that Zn-doping alters the bandgap transition path of BiOBr (Fig. 5). Within the first Brillion zone, the conduction band minima (CBMs) 
of the $\mathrm{BiOBr}$ and $\mathrm{Zn}$-doped $\mathrm{BiOBr}$ samples all locate at $\mathrm{Z}$ points, whereas $\mathrm{Zn}$-doping leads to valance band maxima (VBMs) gradually shift from $\mathrm{R}$ towards $\mathrm{Z}$ point and reduced indirect transition path. The calculated transition results well accord to UV-Vis features (Fig. 4b): increasing Zn-doping levels decreases tangents (slopes) of Tauc plots in bandgap zones.

$\mathrm{BiOBr}$

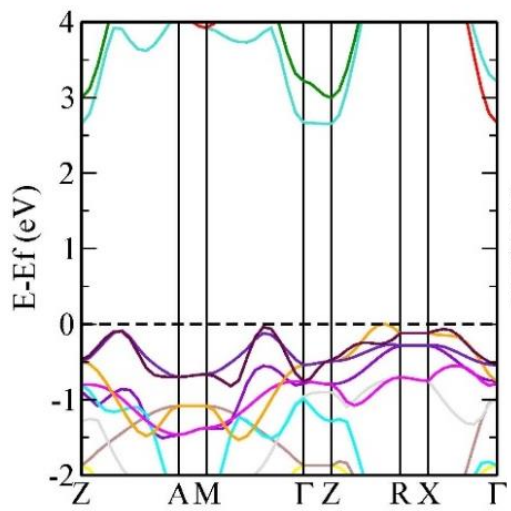

$1 / 16 \mathrm{Zn}-\mathrm{BiOBr}$

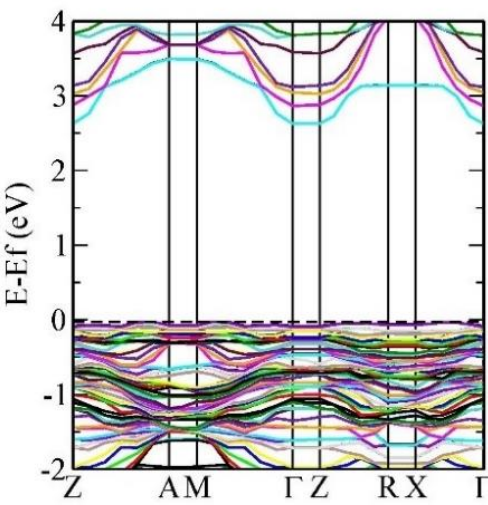

$1 / 8 \mathrm{Zn}-\mathrm{BiOBr}$

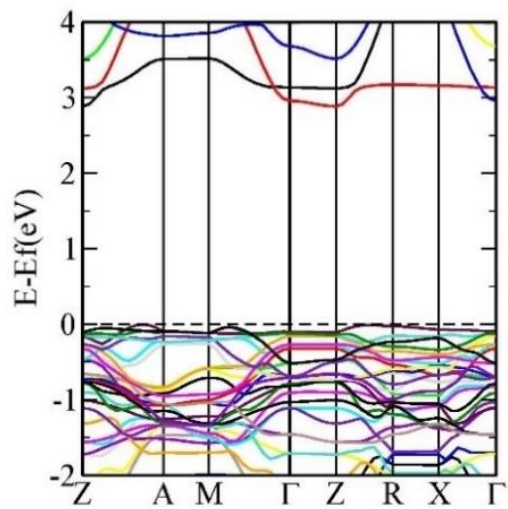

Figure 5 The DFT-simulated bandstructure of the BiOBr, 1/16Zn-BiOBr and 1/8Zn-BiOBr

As compared in Fig. 6, the total DOS and PDOS of pristine and $\mathrm{Zn}$-doped $\mathrm{BiOBr}$ materials further reveal the effects of $\mathrm{Zn}$-doping on the band structure. As shown in Fig. 6a, the CB and CBM of $\mathrm{BiOBr}$ are predominated by $\mathrm{Bi} 6 p$ state, while VB and VBM are mainly occupied by $\mathrm{Br} 4 p$ state with significant hybridisation with $\mathrm{O} 2 p$ and $\mathrm{Bi} 6 s$ electron states $[5,6]$. In contrast, for the representative $\mathrm{Zn}$-doped BiOBr (Fig. 6b), the $\mathrm{Zn} 4 s$ electron states dominate $\mathrm{CBM}$ of $\mathrm{Zn}$-doped $\mathrm{BiOBr}$ with stronger density and slightly hybridises with low-density Bi $6 p$ state above CBM. In addition, the Zn-doping changes the electronic density and components of VB and VBM with slightly lower density of $\mathrm{Br} 4 \mathrm{p}$, $\mathrm{O} 2 \mathrm{p}$ and $\mathrm{Bi}$ 6s states than those of $\mathrm{BiOBr}$.

The Zn-dopant also broadens VB width, which was evidenced experimentally by the broader VB XPS of $\mathrm{Zn}$-doped $\mathrm{BiOBr}$ (Fig. 6d). Comparing the XPS near VBM of the samples (Fig. 6d), one can conclude that Zn-doping pushes the VBM to deeper energy level (more positive), namely higher oxidation potential of VB holes. By extrapolating the valence band edge of the VBM XPS, the VBM potentials are determined of $2.05 \mathrm{eV}, 2.25 \mathrm{eV}$ and $2.31 \mathrm{eV}$ for $\mathrm{BiOBr}, 1 / 16 \mathrm{Zn}-\mathrm{BiOBr}$ and $1 / 8 \mathrm{Zn}-\mathrm{BiOBr}$, respectively. Since XPS spectra were calibrated by C $1 s$ XPS ( $\mathrm{E}_{\mathrm{f}}$ of $\mathrm{C}$ is $\sim 0.3 \mathrm{eV}$ vs RHE), VBM potentials can then be transferred to $2.35,2.55$ and $2.61 \mathrm{eV}$ in RHE scale, agreeing with MottSchottky measurements (Fig. 7). In addition, XPS at VBM edges of Zn-doped BiOBr samples show lower intensity than that of $\mathrm{BiOBr}$, due to the reduced electronic density of $\mathrm{Br} 3 d$, O $2 p$ and $\mathrm{Bi} 6 s$ states which are caused by Zn-doping, as suggested by DOS results (Fig. 6 a c). 

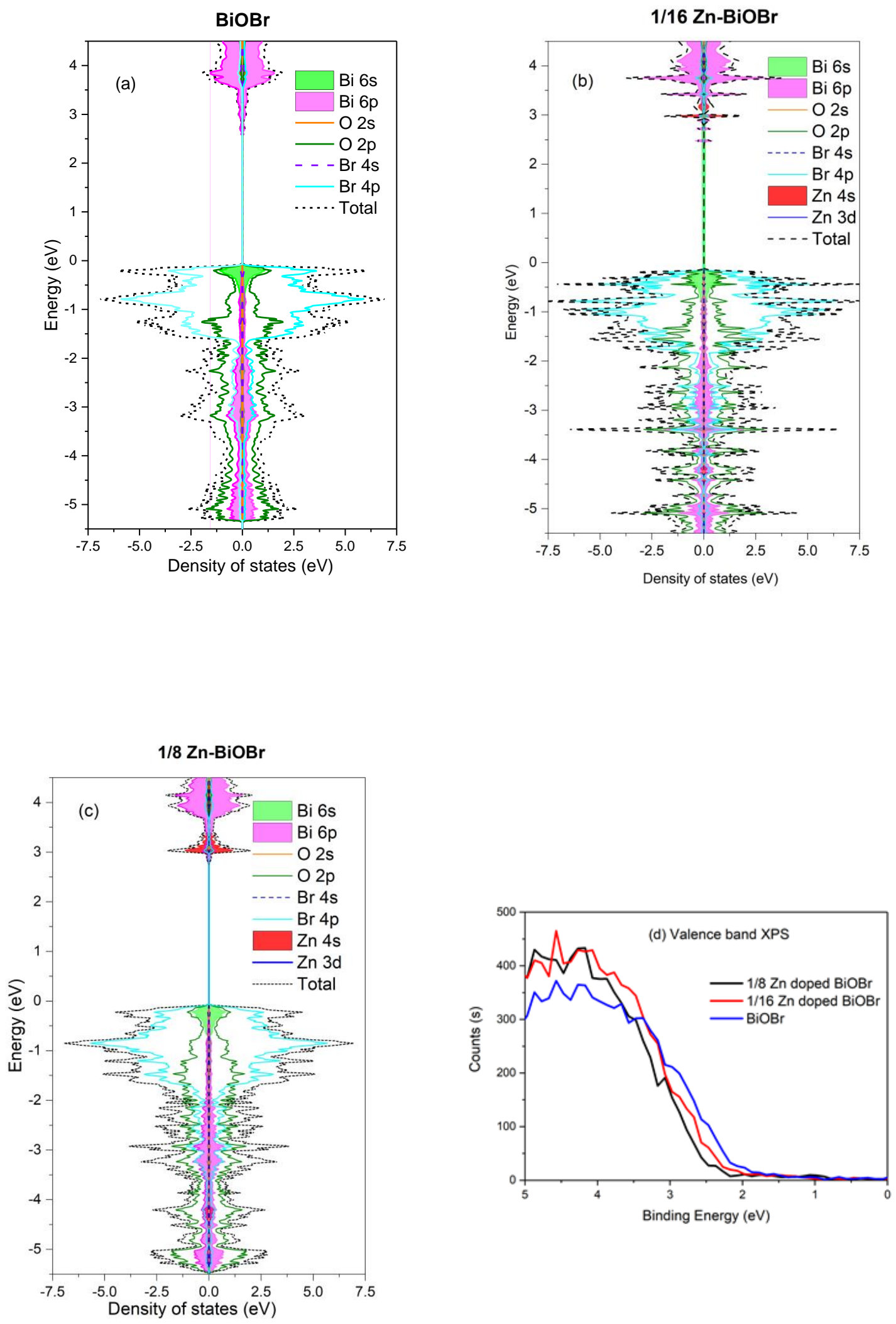

Figure 6 DOS and PDOS of BiOBr (a), 1/16Zn-BiOBr (b) and 1/8ZnBiOBr (c), where DOS of Bi and $\mathrm{Zn}$ are shadowed, and the VBM XPS of pristine and Zn-doped BiOBr samples (d). 
Fig. 7a shows the Mott-Schottky (M-S) plots of $\mathrm{BiOBr}$ and $\mathrm{Zn}$-doped $\mathrm{BiOBr}$ photoanodes, where the positive slopes of the linear regions reveal they are n-type semiconductors [43]. The tangent gradient becomes larger as increasing $\mathrm{Zn}$-doping level in $\mathrm{Zn}-\mathrm{BiOBr}$ samples, suggesting their electron donor density $\left(\mathrm{N}_{\mathrm{d}}\right)$ from VB drops (Table 2) because of the tangent gradient is inversely proportional to majority density[44]. The results well agree with computed bandstructures and DOS of Zn-doped $\mathrm{BiOBr}$ where the flatter band edges suggest less dispersive and heavier $\mathrm{h}^{+}$occupied the VBMs [6].
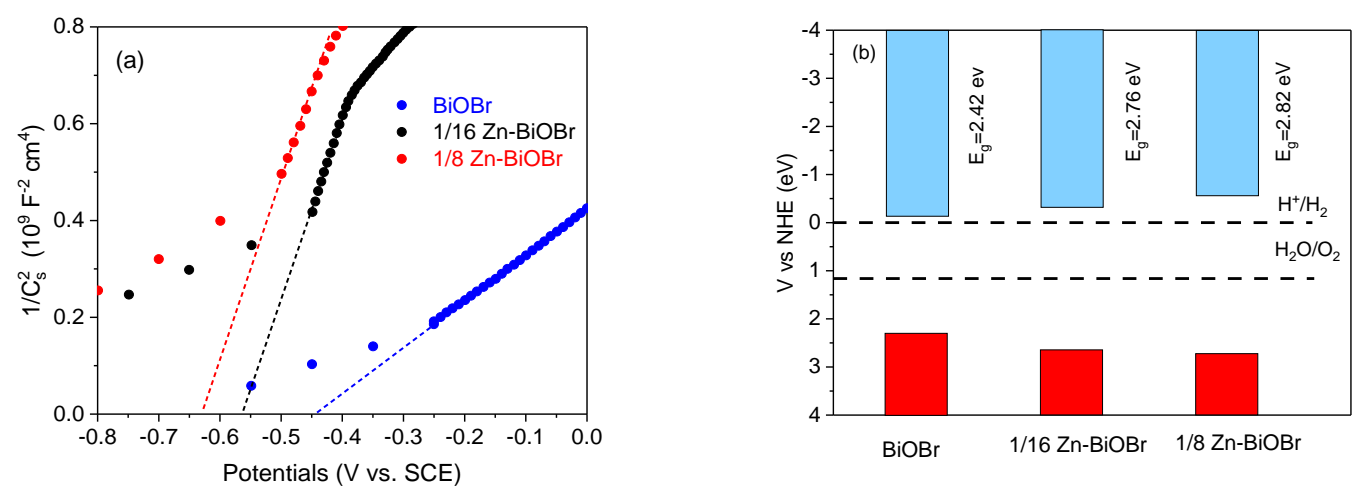

Figure 7 The photoanode Mott-Schottky plots (a) and the derived energy band diagrams vs RHE at $\mathrm{pH}=\mathrm{O}(\mathrm{b})$ of the BiOBr and $\mathrm{Zn}$-doped BiOBr samples

The $\mathrm{E}_{\mathrm{fb} \sim \mathrm{RHE}}, \mathrm{E}_{\mathrm{CBM}}$ and $\mathrm{E}_{\mathrm{VBM}}$ of the samples referring to RHE scale listed in Table 2 were extracted from the M-S plots. Accordingly, the energetic band diagram of $\mathrm{BiOBr}$ and $\mathrm{Zn}$-doped $\mathrm{BiOBr}$ samples can be drawn and illustrated in Fig. 7b. Besides broadening the bandgap (Eg), increases of Zn-doping raise $\mathrm{CBM}$ of $\mathrm{Zn}$-doped $\mathrm{BiOBr}$ to higher level (more negative) but push VBM energy downwards (more positive). The acquired VBM potentials are consistent with those from VB XPS, validating the M-S characterisation is an effective and reliable method to define the chemical potentials of VBM.

Table 2 Photodegradation rate constants and energy band edges (eV) of pure and Zn-doped BiOBr samples

\begin{tabular}{lcccccc}
\hline Photocatalysts & ${\text { Rate constants }\left(\mathbf{m i n}^{-1}\right)}^{-1}$ & $\mathbf{E}_{\text {extro }-S C E}$ & $\mathbf{E}_{\mathrm{fb}-\mathrm{RHE}}$ & $\mathbf{E}_{\mathbf{C B M}-\mathrm{RHE}}$ & $\mathbf{E}_{\text {VвM } \sim \text { RHE }}$ & M-S Slope \\
\hline $\mathrm{BiOBr}$ & 0.1528 & $-0.45 \mathrm{~V}$ & 0.15 & $-0.05 \mathrm{~V}$ & $2.37(2.35)$ & $0.9570 \times 10^{9}$ \\
$1 / 16 \mathrm{Zn}-\mathrm{BiOBr}$ & 0.1357 & $-0.56 \mathrm{~V}$ & 0.04 & $-0.16 \mathrm{~V}$ & $2.60(2.55)$ & $3.7783 \times 10^{9}$ \\
$1 / 8 \mathrm{Zn}-\mathrm{BiOBr}$ & 0.1028 & $-0.62 \mathrm{~V}$ & -0.02 & $-0.22 \mathrm{~V}$ & $2.65(2.61)$ & $3.2109 \times 10^{9}$
\end{tabular}

Note: The bracketed numbers in $\mathrm{E}_{\mathrm{VBM} \sim \mathrm{RHE}}$ column were retrieved from VBM XPS spectra.

\subsection{Photocatalytic water splitting and RhB decomposition}

The band diagrams presented in Fig. $7 \mathrm{~b}$ suggest the $\mathrm{BiOBr}$ and $\mathrm{Zn}$-doped $\mathrm{BiOBr}$ can photocatalyticalyse water splitting [45]. Experimentally, higher photocatalytic hydrogen evolution rate was acquired (Fig. 8a) on the $1 / 16 \mathrm{Zn}-\mathrm{BiOBr}(\sim 29 \mu \mathrm{mol} / \mathrm{g} / \mathrm{h})$ with respect to $\mathrm{BiOBr}(\sim 13$ $\mu \mathrm{mol} / \mathrm{g} / \mathrm{h}$ ). Considering the weaker PL intensity of $1 / 16 \mathrm{Zn}-\mathrm{BiOBr}$ (Fig. S7) than that of BiOBr, the 
enhanced water splitting on $\mathrm{Zn}-\mathrm{BiOBr}$ can be assigned to the stronger redox ability of the photogenerated charge carriers (Fig. 7b) and the suppressed recombination of photogenerated charge carriers, which cancelled the influences from weaker light adsorption of $\mathrm{Zn}-\mathrm{BiOBr}$ than $\mathrm{BiOBr}$.
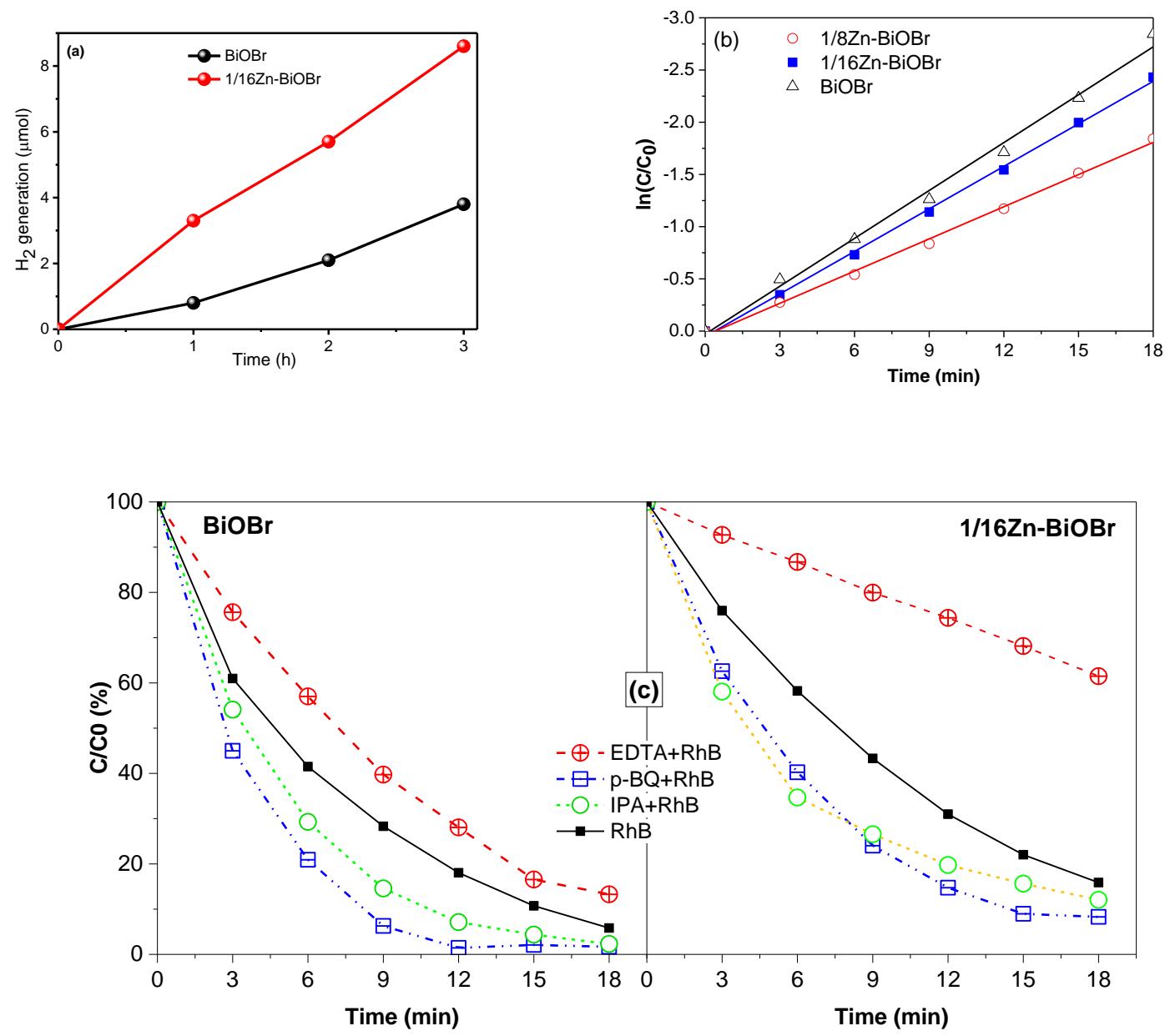

Figure 8 Visible-light photocatalytic water splitting (a) and RhB photodegradation on BiOBr and Zn-

BiOBr samples: (b) apparent kinetic curves and (c) effects of adding radical scaverngers

Fig. $8 \mathrm{~b}$ comparatively shows the apparent photocatalysis kinetics of visible-light-driven photodegradation of $\mathrm{RhB}$ on $\mathrm{BiOBr}$ and the $\mathrm{Zn}$-doped $\mathrm{BiOBr}$ samples. Since the samples displayed similar identical adsorption-desorption equilibrium (Fig. S8) and thus almost identical SSA, their apparent kinetic coefficients can be used to compare their intrinsic microscopic kinetic behaviour. The derived apparent kinetic coefficients $(k$, Table 2$)$ suggest $\mathrm{RhB}$ photodegradation rate is dragged as $\mathrm{Zn}$-doping levels increase, which agree with their apparent activity of RhB photodegradation (black lines in Fig. 8c and Fig. S9). Therefore, the stronger light adsorption of $\mathrm{BiOBr}$ seems responsible for its higher photocatalytic activity than Zn-doped samples, though such interpretation cannot clarify the mechanistic responsibility of the dye-sensitisation and photoexcitons for the redox half reactions. 


\section{Mechanism perspectives of photocatalysis in $\mathrm{RhB}$ photodegradation and $\mathrm{H}_{2}$ evolution}

It is a great challenge to unravel the photocatalytic mechanism in the aqueous photocatalytic system, because it contains aqueous radical intermediates, in particular the hydroxyl radical $(\mathrm{HO} \cdot 1.99 \mathrm{eV}$ vs RHE), $\mathrm{H}_{2} \mathrm{O}_{2}$ (1.77 eV vs RHE) and superoxygen radicals $\left(\cdot \mathrm{O}_{2}^{-},-0.046 \mathrm{eV}\right.$ vs RHE) [3]. The radicals possess strong redox power and can compete with $\mathrm{e}^{-}$and $\mathrm{h}^{+}$from excited photocatalysts or dye. Comparing the redox potentials of the aqueous radicals with band edges of the photocatalysts (Fig. $7 \mathrm{~b}$ and Table 2), redox potentials of LUMO and HOMO of excited $\mathrm{RhB}$ and $\mathrm{H}^{+}$, the major elementary reactions involved in the photocatalytic reactions are proposed and illustrated in Fig. 9.

\subsection{Mechanism interpretation of $\mathrm{H}_{2}$ evolution}

From the chemical potential point of view, the bandstructure of $\mathrm{BiOBr}$ and $\mathrm{Zn}-\mathrm{BiOBr}$ photocatalysts imply they can enable $\mathrm{H}_{2}$ evolution from the methanol-sacrificial water splitting systems. On one hand, chemical potentials of photogenerated $\mathrm{e}^{-}$from $\mathrm{CBs}$ of $\mathrm{BiOBr}$ and $\mathrm{Zn}-\mathrm{BiOBr}$ photocatalysts are more negative than $\mathrm{H}^{+}$reduction $\left(\mathrm{E}_{\mathrm{H}}^{+} / \mathrm{H} 2=0 \mathrm{eV}\right.$ s $\mathrm{RHE}$ ) (Fig. 9a), so $\mathrm{H}_{2}$ was able to release in absence of other $\mathrm{e}^{-}$scavengers (i.e. dissolved $\mathrm{O}_{2}$ ) apart from $\mathrm{H}^{+}$. On the other hand, methanol can largely scavenge $\mathrm{h}^{+}$accumulated on surface of the BiOBr-based photocatalysts, which facilitate $\mathrm{e}^{-}$ transferring to catalyst surface for proton reduction. Bearing in mind, the I-t plot (Fig. 10a) is not effective to interpret water splitting because methanol wasn't used in chronoamperometry tests.
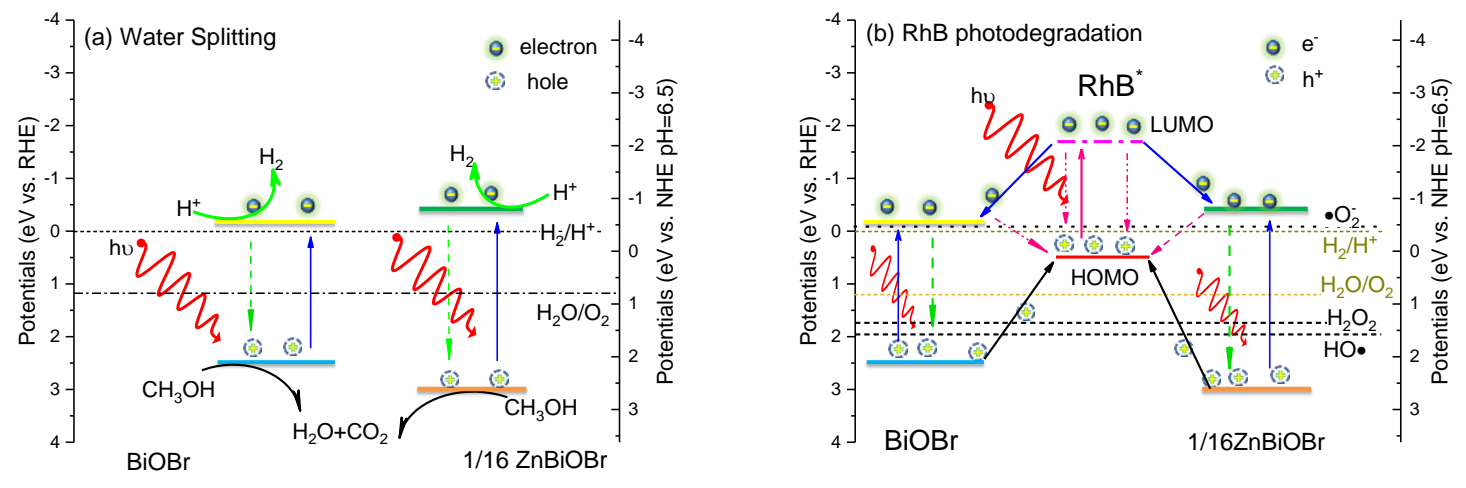

Fig. 9 The schematic mechanisms of photocatalytic water splitting (a) and RhB degradation (b)

The enhanced photocatalytic $\mathrm{H}_{2}$ evolution due to $\mathrm{Zn}$-doping can be interpreted from bandstructure and $\mathrm{e}^{-}-\mathrm{h}^{+}$recombination aspects. From the thermodynamic point of view, the $\mathrm{H}_{2}$ evolution on $\mathrm{Zn}-\mathrm{BiOBr}$ is more favourable, because the potential energy difference $\left(\Delta \mathrm{E}_{\mathrm{CBM}^{\sim} \mathrm{H}^{+} / \mathrm{H} 2}=\mathrm{E}_{\mathrm{CBM}}-\mathrm{E}_{\mathrm{H}}{ }^{+} / \mathrm{H} 2\right)$ between $\mathrm{E}_{\mathrm{CBM}}$ and $\mathrm{E}_{\mathrm{H}}{ }^{+} / \mathrm{H} 2$ on $\mathrm{Zn}-\mathrm{BiOBr}$ is more negative than $\Delta \mathrm{E}_{\mathrm{CBM} \sim \mathrm{H}^{+} / \mathrm{H} 2}$ on $\mathrm{BiOBr}$, which is the driving force to promote photogeneration of $\mathrm{H}_{2}$ : First, photogenerated $\mathrm{e}^{-}$from $1 / 16 \mathrm{Zn}-\mathrm{BiOBr}$ is more reductive $\left(\mathrm{E}_{\mathrm{CBM}}\right.$ more negative, Fig. 9a) as compared to that of $\mathrm{BiOBr}$. The more negative $\Delta \mathrm{E}_{\mathrm{CBM}^{\sim} \mathrm{H}^{+} / \mathrm{H} 2}$ on $1 / 16 \mathrm{Zn}$ - 
$\mathrm{BiOBr}$ is helpful to limit the back reaction of $\mathrm{H}^{+}$reduction. Second and more importantly, the $\mathrm{e}^{-}-\mathrm{h}^{+}$ recombination of $\mathrm{BiOBr}$ is nearly four-fold that of $1 / 16 \mathrm{Zn}-\mathrm{BiOBr}$ as reflected by their PL spectra (Fig. S7). Such strong recombination on $\mathrm{BiOBr}$ would cancel its advantage on light absorption. Therefore, the higher reductive of $\mathrm{CBM} \mathrm{e}^{-}$, limited back reaction and larger amount of reactive $\mathrm{e}^{-}$are responsible for superior $\mathrm{H}_{2}$ evolution on $\mathrm{Zn}$-doped to pristine $\mathrm{BiOBr}$.

\subsection{Mechanism interpretation of $\mathrm{RhB}$ photodegradation}

For the energy downhill photodegradation of $\mathrm{RhB}$, the competition of photoexcitons $\left(\mathrm{e}^{-}-\mathrm{h}^{+}\right)$at band edges of photocatalysts with radical derivatives as well as dye photosensitisation effects can be defined from critical analyses of the results of radical scavenger and chronoamperometry experiments.

\subsubsection{Rate-limiting species in RhB Photodegradation}

As comparatively shown in Fig. 8c, photocatalytic activities on the pristine and $\mathrm{Zn}$-doped $\mathrm{BiOBr}$ samples are found being enhanced significantly as adding either $\cdot \mathrm{O}_{2}^{-}$scavenger (p-BQ) or HO• (isopropanol, IPA) into respective $\mathrm{RhB}$ photodegradation systems [46]. These results can roughly rule out that $\mathrm{O}_{2}{ }^{-}$and $\mathrm{HO} \cdot$ radicals limit $\mathrm{RhB}$ photodegradation because the radicals were consumed rapidly by scavengers, leading to enhanced availability of photogenerated $\mathrm{h}^{+}$. The $\mathrm{p}-\mathrm{BQ}$ and IPA quenching experiments also reflect that photogenerated holes are perhaps rate-limiting species. The vital rate-determining roles of $\mathrm{h}^{+}$were verified by dramatically declined $\mathrm{RhB}$ degradation activity when adding EDTA-Na ( $\mathrm{h}^{+}$scavenger) [16].

In the photocatalytic system, $\cdot \mathrm{O}_{2}^{-}$should be related to the photogenerated electrons at $\mathrm{CBMs}$ of $\mathrm{BiOBr}$ and $\mathrm{Zn}-\mathrm{BiOBr}$ samples because their CBMs are more negative than ${ }^{\circ} \mathrm{O}_{2}{ }^{-}$formation energy (Fig. $9 \mathrm{~b}$ ). Taking account of the more negative LUMO of $\mathrm{RhB}$ (-1.77 eV vs RHE) than CBMs[47], the photogenerated electrons at $\mathrm{CBM}$ can be injected from both excited $\mathrm{RhB}$ (photosensitisation effects) and excited photocatalysts. The $\mathrm{HOMO}$ of $\mathrm{RhB}^{*}(0.47 \mathrm{eV})$ is more positive than ${ }^{-} \mathrm{O}_{2}^{-}$formation energy $(-0.05 \mathrm{eV})$, so the recombination between the $\mathrm{HOMO} \mathrm{h}^{+}$and $\cdot \mathrm{O}_{2}{ }^{-}$can be occurred. However, the p-BQ can quench ${ }^{\circ} \mathrm{O}_{2}{ }^{-}$in the $\mathrm{RhB}$ photodegradation system that restrains the recombination as well as promote the $\mathrm{VBM} \mathrm{h}^{+}$, hence, $\mathrm{p}-\mathrm{BQ}$ enhanced $\mathrm{RhB}$ photodegradation was observed.

The IPA enhanced RhB photodegradation likely follows the same mechanism if the photogenerated HO- radicals are induced by $\mathrm{e}^{-}$from CBMs (Fig.9b). Since the HO- radical is more energetically positive than HOMO of $\mathrm{RhB}^{*}$ but more negative than holes of photocatalysts VBMs, HO radicals can accept holes from VBMs but cannot accept $\mathrm{h}^{+}$from HOMO of RhB*. However, the IPA quenched $\mathrm{HO}$ - radicals, which can consume more electrons and reduce their recombination to $\mathrm{h}^{+}$at VBMs as a result of IPA-enhanced RhB photodegradation on all the BiOBr-based samples (Fig. 8c). 
The addition of EDTA caused more significantly decline of RhB photodegradation rate on the Zndoped than the pristine $\mathrm{BiOBr}$, indicating VBM holes are rate-limiting species for the present photodegradation reaction. This is reasonable because $\mathrm{VBM}$ of $\mathrm{Zn}-\mathrm{BiOBr}$ is more positive and holes more oxidative than those of $\mathrm{BiOBr}$ and $\mathrm{RhB}$ HOMO (Fig.9b). Although the above apparent photocatalysis and scavenger experiments can roughly define the roles of reactive species, the RhB photosensitisation effects remains quantified insufficiently.

\subsubsection{RhB dye photosensitisation effects}
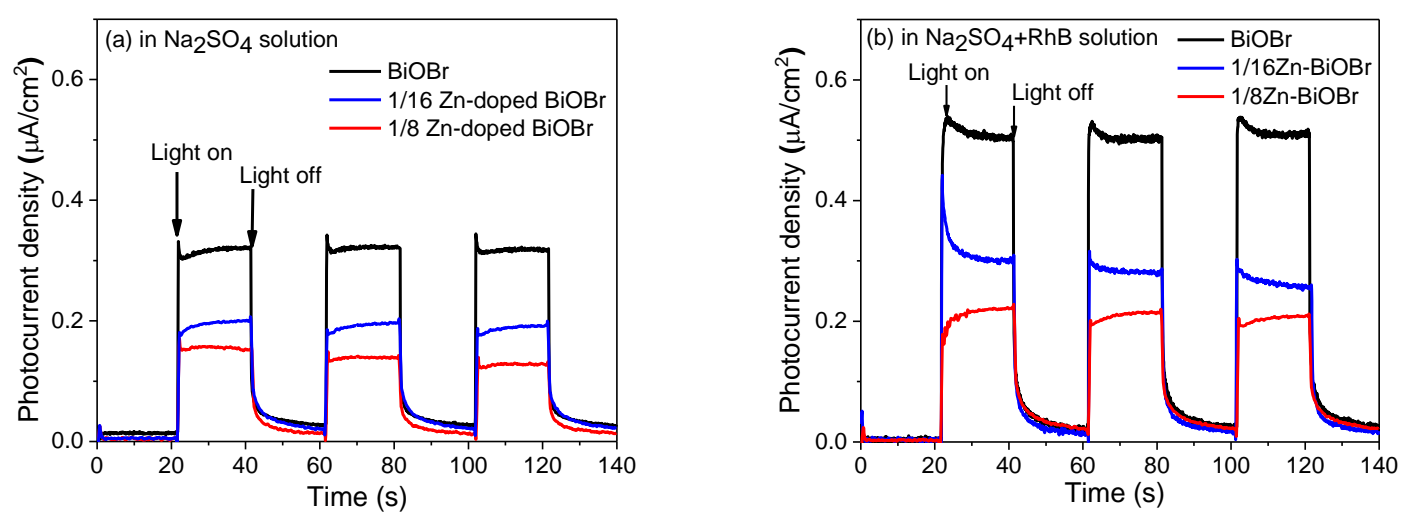

Figure 10 Temporary photocurrent density acquired on the BiOBr and $\mathrm{Zn}$-doped BiOBr photoelectrodes in $\mathrm{Na}_{2} \mathrm{SO}_{4}$ electrolyte solutions without (a) and with $20 \mathrm{ppm} \mathrm{RhB} \mathrm{(b).}$

Table3 Temporal photocurrents on the pristine and $\mathrm{Zn}$-doped $\mathrm{BiOBr}$ photoelectrodes

\begin{tabular}{ccccc}
\hline & \multicolumn{4}{c}{ Photocurrent density $\left(\mathrm{J}, \mu \mathrm{A} / \mathrm{cm}^{2}\right)^{\mathrm{a}}$} \\
& $\mathrm{J}_{\mathrm{PC}}$ & $\mathrm{J}_{\mathrm{RhB} / \mathrm{PC}}$ & $\Delta \mathrm{J}^{\mathrm{b}}$ & $\Delta \mathrm{J} / \mathrm{J}_{\mathrm{PC}}(\%)^{\mathrm{c}}$ \\
\hline $\mathrm{BiOBr}$ & 0.32 & 0.51 & 0.19 & $+59.4 \%$ \\
$1 / 16 \mathrm{Zn}-\mathrm{BiOBr}$ & 0.19 & 0.30 & 0.11 & $+57.9 \%$ \\
$1 / 8 \mathrm{Zn}-\mathrm{BiOBr}$ & 0.13 & 0.21 & 0.08 & $+61.5 \%$
\end{tabular}

Note: a.) The photocurrent density ( $\mathrm{J}$ ) data were collected at $\mathrm{V}_{\mathrm{OC}}$ of corresponding photoelectrode, where $\mathrm{J}_{\mathrm{PC}}$ and $\mathrm{J}_{\mathrm{RhB} / \mathrm{PC}}$ represent $\mathrm{J}$ values acquired in $0.5 \mathrm{M} \mathrm{Na}_{2} \mathrm{SO}_{4}$ without and with $20 \mathrm{ppm} \mathrm{RhB}$ solution, respectively. b.) The absolute photocurrent density enhancement due to dye-sensitisation, $\Delta J=J_{R h B / P C}-J_{P C}$. c.) The relative enhancement in percentage due to dye-sensitisation, calculated by $\Delta \mathrm{J} / \mathrm{J}_{\mathrm{PC}} * 100 \%$.

The dye photosensitisation effects on the RhB photocatalytic degradation over the BiOBr-based photocatalysts were evaluated by chronoamperometrical experiments at open circuit potentials ( $\left.\mathrm{V}_{\mathrm{OC}}\right)$. Fig. 10 shows the acquired temporary photocurrent density against light on-off time (J-t plots) of the BiOBr-based photoelectrodes in $0.5 \mathrm{M} \mathrm{Na}_{2} \mathrm{SO}_{4}$ without (Fig. 10a) and with (Fig. 10b) 20 ppm RhB 


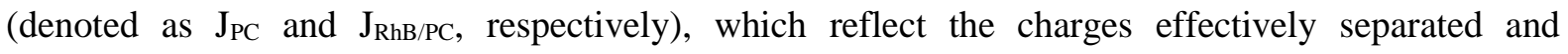
transferred onto the photocatalysts surface. Apparently, $\mathrm{RhB}$ photosensitisations dramatically promote the photocurrent density on all the $\mathrm{BiOBr}$ and $\mathrm{Zn}$-doped $\mathrm{BiOBr}$ samples, in the 57\% 62\% enhancement range $\left(\Delta \mathrm{J} / \mathrm{J}_{\mathrm{PC}} \times 100 \%\right)$. Although the relative enhancement ratios are comparable, the quantitative comparison of the photocurrents (Table 3) suggests the absolute photocurrent density enhancements $(\Delta \mathrm{J})$ due to dye photosensitisation declines as increasing $\mathrm{Zn}$-doping level.

\section{Conclusion}

The Zn-doping effects on $\mathrm{RhB}$ photodegradation over $\mathrm{Zn}$-doped $\mathrm{BiOBr}$, synthesised via a simple alkaline co-precipitation method, was convincingly clarified from energy and reactive species perspectives, through comprehensive spectral, DFT and photoelectrochemical investigations on the crystal structure, optoelectronic properties and photoelectrocatalysis of pristine and $\mathrm{Zn}$-doped $\mathrm{BiOBr}$. Under visible-light illumination, the $\mathrm{Zn}$-doping in $\mathrm{BiOBr}$ was found showing higher $\mathrm{H}_{2}$ evolution activity than $\mathrm{BiOBr}$ but detrimental activity in $\mathrm{RhB}$ photodegradation.

The comparative experimental and DFT characterisations of pure and $\mathrm{Zn}$-doped $\mathrm{BiOBr}$ revealed that $\mathrm{Zn}$-doping shrinks the lattice of $\mathrm{BiOBr}$ thought $\mathrm{Zn}$-doped $\mathrm{BiOBr}$ samples remain indirect bandgap charge transitions. Distinct from the doping effects of other metals with unclosed $d$ or $f$ electronic shells, the $\mathrm{Zn}$-doping in $\mathrm{BiOBr}$ was found expanding the bandgap by enhancing CBM and deepening VBM: The CBMs of $\mathrm{Zn}$-doped $\mathrm{BiOBr}$ mainly compose of $\mathrm{Zn} 4 s$ electron state with slight hybridisation to lower $\mathrm{Bi} 6 p$ state that predominates the $\mathrm{CBM}$ of $\mathrm{BiOBr}$, while VBMs of $\mathrm{Zn}$-doped $\mathrm{BiOBr}$ comprise $\mathrm{Br} 3 \mathrm{~d}, \mathrm{O} 2 \mathrm{p}$ and $\mathrm{Bi}$ 6s states which is very similar to $\mathrm{BiOBr}$ except for reduced density due to $\mathrm{Zn}$-doping. It was also found that the closed $\mathrm{Zn} 3 d^{10}$ electrons locating in deeper band with negligible influence on VBM with respective to $\mathrm{BiOBr}$ while $\mathrm{Zn}$-dopant donates core electrons to surrounding atoms.

The enhanced water splitting on $\mathrm{Zn}$-doping to $\mathrm{BiOBr}$ in the methanol-sacrificial photocatalytic systems were attributed to the higher reactivity of charge carriers on band edges, the reduced back reaction of proton photo-reduction and the lower recombination of charge carriers on $\mathrm{Zn}$-doped $\mathrm{BiOBr}$, which altogether contributed more than light absorption in water splitting. However, the ratelimiting reactive species were confirmed photogenerated holes on the $\mathrm{BiOBr}$-based materials in spite of multiple reactive radicals involved in the complex dye photodegradation system. The detrimental photocatalytic activities on $\mathrm{Zn}$-doped $\mathrm{BiOBr}$ samples were reasonably attributed to the comprehensive results of the weaker light absorption and reduced dye-sensitisation effects besides the surface photogenerated electrons and holes.

\section{Acknowledgements}


This work was partially supported by the Zipler Institute grant at University of Southampton, the Newton Fund International Collaboration (NRCP1415/261) and the Royal Society International collaboration awards (IECINSFCl170670 and IE160277). JG and XL appreciate the Eustice studentship from Southampton University. The authors acknowledge the use of the IRIDIS High Performance Computing Facility and associated support services at the University of Southampton, in the completion of this work.

\section{References}

[1] D.S. Bhachu, S.J.A. Moniz, S. Sathasivam, D.O. Scanlon, A. Walsh, S.M. Bawaked, M. Mokhtar, A.Y. Obaid, I.P. Parkin, J. Tang, C.J. Carmalt, Bismuth oxyhalides: synthesis, structure and photoelectrochemical activity, Chem. Sci., (2016).

[2] J. Shang, W. Hao, X. Lv, T. Wang, X. Wang, Y. Du, S. Dou, T. Xie, D. Wang, J. Wang, Bismuth Oxybromide with Reasonable Photocatalytic Reduction Activity under Visible Light, ACS Catal., 4 (2014) 954-961.

[3] Z. Jiang, F. Yang, G. Yang, L. Kong, M.O. Jones, T. Xiao, P.P. Edwards, The hydrothermal synthesis of $\mathrm{BiOBr}$ flakes for visible-light-responsive photocatalytic degradation of methyl orange, J. Photoch. Photobio. A, 212 (2010) 8-13.

[4] Z.Y. Zhao, W.W. Dai, Structural, electronic, and optical properties of Eu-doped BiOX (X $=\mathrm{F}, \mathrm{Cl}, \mathrm{Br}$, I): a DFT+U study, Inorg Chem, 53 (2014) 13001-13011.

[5] W.L. Huang, Electronic structures and optical properties of $\mathrm{BiOX}(\mathrm{X}=\mathrm{F}, \mathrm{Cl}, \mathrm{Br}, \mathrm{I})$ via DFT calculations, J. Comput. Chem., 30 (2009) 1882-1891.

[6] W.L. Huang, Q. Zhu, DFT calculations on the electronic structures of $\mathrm{BiOX}(\mathrm{X}=\mathrm{F}, \mathrm{Cl}, \mathrm{Br}, \mathrm{I})$ photocatalysts with and without semicore Bi 5 d states, J Comput. Chem., 30 (2009) 183-190.

[7] J. Wang, N. Tafen de, J.P. Lewis, Z. Hong, A. Manivannan, M. Zhi, M. Li, N. Wu, Origin of photocatalytic activity of nitrogen-doped TiO2 nanobelts, J. Am. Chem. Soc, 131 (2009) 12290-12297. [8] A.S. Alshammari, L. Chi, X. Chen, A. Bagabas, D. Kramer, A. Alromaeh, Z. Jiang, Visible-light photocatalysis on C-doped ZnO derived from polymer-assisted pyrolysis, RSC Adv., 5 (2015) 2769027698.

[9] A. Dash, S. Sarkar, V.N. Adusumalli, V. Mahalingam, Microwave synthesis, photoluminescence, and photocatalytic activity of PVA-functionalized Eu3+-doped $\mathrm{BiOX}(\mathrm{X}=\mathrm{Cl}, \mathrm{Br}, \mathrm{I})$ nanoflakes, Langmuir, 30 (2014) 1401-1409.

[10] C. Bi, J. Cao, H. Lin, Y. Wang, S. Chen, Tunable photocatalytic and photoelectric properties of I-doped BiOBr photocatalyst: dramatic pH effect, RSC Adv., 6 (2016) 15525-15534.

[11] Z. Liu, B. Wu, Y. Zhao, J. Niu, Y. Zhu, Solvothermal synthesis and photocatalytic activity of Aldoped BiOBr microspheres, Ceram. Int, 40 (2014) 5597-5603.

[12] M.Q. He, W.B. Li, J.X. Xia, L. Xu, J. Di, H. Xu, S. Yin, H.M. Li, M.N. Li, The enhanced visible light photocatalytic activity of yttrium-doped $\mathrm{BiOBr}$ synthesized via a reactable ionic liquid, Appl Surf Sci, 331 (2015) 170-178.

[13] R.J. Wang, G.H. Jiang, X.H. Wang, R.B. Hu, X.G. Xi, S.Y. Bao, Y. Zhou, T. Tong, S. Wang, T. Wang, W.X. Chen, Efficient visible-light-induced photocatalytic activity over the novel Ti-doped $\mathrm{BiOBr}$ microspheres, Powder Technol, 228 (2012) 258-263.

[14] G.H. Jiang, X. Li, Z. Wei, X.H. Wang, T.T. Jiang, X.X. Du, W.X. Chen, Immobilization of N, Scodoped $\mathrm{BiOBr}$ on glass fibers for photocatalytic degradation of rhodamine B, Powder Technol, 261 (2014) 170-175.

[15] Z. Wei, G.H. Jiang, L. Shen, X. Li, X.H. Wang, W.X. Chen, Preparation of Mn-doped BiOBr microspheres for efficient visible-light-induced photocatalysis, MRS Commun., 3 (2013) 145-149. 
[16] X.C. Song, Y.F. Zheng, H.Y. Yin, J.N. Liu, X.D. Ruan, The solvothermal synthesis and enhanced photocatalytic activity of $\mathrm{Zn2}+$ doped $\mathrm{BiOBr}$ hierarchical nanostructures, New J. Chem., 40 (2016) 130-135.

[17] G.H. Jiang, X.H. Wang, Z. Wei, X. Li, X.G. Xi, R.B. Hu, B.L. Tang, R.J. Wang, S. Wang, T. Wang, W.X. Chen, Photocatalytic properties of hierarchical structures based on Fe-doped $\mathrm{BiOBr}$ hollow microspheres, J. Mater. Chem. A, 1 (2013) 2406-2410.

[18] L. Ye, J. Liu, C. Gong, L. Tian, T. Peng, L. Zan, Two different roles of metallic Ag on Ag/AgX/BiOX $(\mathrm{X}=\mathrm{Cl}, \mathrm{Br})$ visible light photocatalysts: Surface plasmon resonance and Z-Scheme bridge, ACS Catalysis, 2 (2012) 1677-1683.

[19] C. Yu, C. Fan, X. Meng, K. Yang, F. Cao, X. Li, A novel Ag/BiOBr nanoplate catalyst with high photocatalytic activity in the decomposition of dyes, Reaction Kinetics, Mechanisms and Catalysis, 103 (2011) 141-151.

[20] L. Lu, L. Kong, Z. Jiang, H.H.C. Lai, T. Xiao, P.P. Edwards, Visible-light-driven photodegradation of rhodamine B on Ag-modified BiOBr, Catal. Lett., 142 (2012) 771-778.

[21] L. Kong, Z. Jiang, H.H.C. Lai, T. Xiao, P.P. Edwards, Does noble metal modification improve the photocatalytic activity of BiOCl? Prog. Nat. Sci.: Mater. Intern., 23 (2013) 286-293.

[22] D. Jiang, L. Chen, J. Zhu, M. Chen, W. Shi, J. Xie, Novel p-n heterojunction photocatalyst constructed by porous graphite-like $\mathrm{C} 3 \mathrm{~N} 4$ and nanostructured $\mathrm{BiOl}$ : facile synthesis and enhanced photocatalytic activity, Dalton trans., 42 (2013) 15726-15734.

[23] S.K. Poznyak, A.I. Kulak, Photoelectrochemical properties of bismuth oxyhalide films, Electrochimica Acta, 35 (1990) 1941-1947.

[24] F.E. Osterloh, Photocatalysis versus Photosynthesis: A Sensitivity Analysis of Devices for Solar Energy Conversion and Chemical Transformations, ACS Energy Letters, 2 (2017) 445-453.

[25] K. Takanabe, Photocatalytic Water Splitting: Quantitative Approaches toward Photocatalyst by Design, ACS Catal., 7 (2017) 8006-8022.

[26] H. Cheng, B. Huang, Y. Dai, Engineering BiOX $(X=\mathrm{Cl}, \mathrm{Br}, \mathrm{I})$ nanostructures for highly efficient photocatalytic applications, Nanoscale, 6 (2014) 2009-2026.

[27] L. Kong, Z. Jiang, H.H. Lai, R.J. Nicholls, T. Xiao, M.O. Jones, P.P. Edwards, Unusual reactivity of visible-light-responsive $\mathrm{AgBr}-\mathrm{BiOBr}$ heterojunction photocatalysts, J. Catal., 293 (2012) 116-125.

[28] X.C. Zhang, C.M. Fan, Y.W. Wang, Y.F. Wang, Z.H. Liang, P.D. Han, DFT+U predictions: The effect of oxygen vacancy on the structural, electronic and photocatalytic properties of $\mathrm{Mn}$-doped $\mathrm{BiOCl}$, Comput. Mater. Sci, 71 (2013) 135-145.

[29] D.M. Jang, I.H. Kwak, E.L. Kwon, C.S. Jung, H.S. Im, K. Park, J. Park, Transition-Metal Doping of Oxide Nanocrystals for Enhanced Catalytic Oxygen Evolution, J. Phys. Chem. C, 119 (2015) 1921-1927. [30] Z.Y. Zhao, Q.L. Liu, W.W. Dai, Structural, Electronic, and Optical Properties of BiOX1-XYX (X, Y = F, $\mathrm{Cl}, \mathrm{Br}$, and I) Solid Solutions from DFT Calculations, Sci. Rep., 6 (2016) 31449.

[31] W. Li, Y. Zou, X. Geng, F. Xiao, G. An, D. Wang, Constructing highly catalytic oxidation over $\mathrm{BiOBr}$-based hierarchical microspheres: Importance of redox potential of doped cations, Mol. Catal., 438 (2017) 19-29.

[32] L. Kong, Z. Jiang, T. Xiao, L. Lu, M.O. Jones, P.P. Edwards, Exceptional visible-light-driven photocatalytic activity over BiOBr-ZnFe2O4 heterojunctions, Chem Commun, 47 (2011) 5512-5514.

[33] G. Jiang, R. Wang, X. Wang, X. Xi, R. Hu, Y. Zhou, S. Wang, T. Wang, W. Chen, Novel highly active visible-light-induced photocatalysts based on $\mathrm{BiOBr}$ with Ti doping and Ag decorating, ACS Appl. Mater. Interf., 4 (2012) 4440-4444.

[34] C. Piliego, M. Manca, R. Kroon, M. Yarema, K. Szendrei, M.R. Andersson, W. Heiss, M.A. Loi, Charge separation dynamics in a narrow band gap polymer-PbS nanocrystal blend for efficient hybrid solar cells, J. Mater. Chem., 22 (2012) 24411-24416.

[35] K.F. Zhang, W. Zhou, L.N. Chi, X.C. Zhang, W.Y. Hu, B.J. Jiang, K. Pan, G.H. Tian, Z. Jiang, Black $\mathrm{N} / \mathrm{H}$ - TiO2 Nanoplates with a Flower - Like Hierarchical Architecture for Photocatalytic Hydrogen Evolution, ChemSusChem, 9 (2016) 2841-2848. 
[36] T. Tan, D. Beydoun, R. Amal, Effects of organic hole scavengers on the photocatalytic reduction of selenium anions, J Photoch. Photobio. A, 159 (2003) 273-280.

[37] S.J. Clark, M.D. Segall, C.J. Pickard, P.J. Hasnip, M.I.J. Probert, K. Refson, M.C. Payne, First principles methods using CASTEP, Zeitschrift fur Kristallographie, 220 (2005) 567-570.

[38] Y. Kato, R. Nagao, T. Noguchi, Redox potential of the terminal quinone electron acceptor QB in photosystem II reveals the mechanism of electron transfer regulation, Proc Natl Acad Sci U S A, 113 (2016) 620-625.

[39] H.T. Hsu, S.S. Chen, Y.F. Tang, H.C. Hsi, Enhanced photocatalytic activity of chromium(VI) reduction and EDTA oxidization by photoelectrocatalysis combining cationic exchange membrane processes, J Hazard. Mater., 248-249 (2013) 97-106.

[40] J.H. Kennedy, Flatband Potentials and Donor Densities of Polycrystalline $\alpha$-Fe[sub 2]O[sub 3] Determined from Mott-Schottky Plots, J. Electrochem. Soc., 125 (1978) 723.

[41] S.R. Morrison, Electrochemistry at semiconductor and oxidized metal electrodes, Plenum Press, 1980.

[42] R.D. Shannon, Revised Effective lonic-Radii and Systematic Studies of Interatomic Distances in Halides and Chalcogenides, Acta Crystallogr. A, 32 (1976) 751-767.

[43] P. Kwolek, K. Szacilowski, Photoelectrochemistry of n-type bismuth oxyiodide, Electrochim. Acta, 104 (2013) 448-453.

[44] K. Gelderman, L. Lee, S.W. Donne, Flat-Band Potential of a Semiconductor: Using the MottSchottky Equation, J. Chem. Educ., 84 (2007) 685.

[45] X.Y. Kong, W.P.C. Lee, W.-J. Ong, S.-P. Chai, A.R. Mohamed, Oxygen-Deficient BiOBr as a Highly Stable Photocatalyst for Efficient CO2 Reduction into Renewable Carbon-Neutral Fuels, ChemCatChem, 8 (2016) 3074-3081.

[46] Q. Liu, Y.R. Guo, Z.H. Chen, Z.G. Zhang, X.M. Fang, Constructing a novel ternary $\mathrm{Fe}(\mathrm{III}) /$ graphene/g-C3N4 composite photocatalyst with enhanced visible-light driven photocatalytic activity via interfacial charge transfer effect, Appl Catal B, 183 (2016) 231-241.

[47] H. Zhao, Y. Zhang, G. Li, F. Tian, H. Tang, R. Chen, Rhodamine B-sensitized BiOCl hierarchical nanostructure for methyl orange photodegradation, RSC Adv., 6 (2016) 7772-7779. 